\title{
Determination of a sensitive period for the induction of the maternal pregnancy reaction in the ferret
}

\author{
A. P. Gulamhusein and F. Beck \\ Department of Anatomy, University of Leicester, University Road, \\ Leicester LEI 7RH, U.K.
}

Traumatization of an isolated segment of the ferret uterus on Day 12 of gestation (the day of implantation) results in the development of a maternal pregnancy reaction at the site of the trauma. This reaction consists of the formation and subsequent necrosis of symplasmal nests of endometrial epithelial cells and hypertrophy of the maternal capillary endothelium, and the cytology is identical to that of the endometrial reaction in the placental region of the uterus during normal pregnancy (Beck, 1974). The development of a maternal pregnancy reaction at times during gestation other than Day 12 has not been investigated and the present study was therefore undertaken to see whether a sensitive period existed.

The experimental procedure for isolation of a portion of the uterine horn was similar to that described by Beck (1974). Forty ferrets were mated at oestrus and the day of mating was designated as Day 0 of pregnancy. In 28 animals in Exp. 1 a thick (R.823 Mersilk: Ethicon) silk thread was placed in the lumen of a previously isolated segment of uterine horn at various times before or after implantation; the thread remained in situ until the animals were killed 8 days later. In Exp. 2 the endometrium of the isolated segment in 12 animals was similarly traumatized but the silk thread was removed after $24 \mathrm{~h}$ and the animals were killed 7 days later. Sections through the treated portions of the same uterine horn were fixed in Bouin's fluid and prepared for light microscopy.

The results are summarized in Table 1. Histological examination of the traumatized endometrium of the animals in Exp. 1 showed that a maternal pregnancy reaction developed only at certain stages of gestation. Histological changes appeared most pronounced when the intrauterine thread was inserted on Day 12. No specific response was elicited before Day 6 or after Day 14; traumatization of the endometrium outside the sensitive period merely produced occasional patches of surface necrosis involving not only the epithelium and connective tissue but also the capillaries. The period of sensitivity occurred only between Days 9 and 14 in Exp. 2.

Table 1. The induction of a maternal pregnancy reaction in ferrets (no. in parenthesis) traumatized by a silk thread on different days of gestation

\begin{tabular}{lcccccccccccccccc}
\hline & \multicolumn{11}{c}{ Day of pregnancy } \\
\cline { 2 - 14 } & 2 & 3 & 4 & 5 & 6 & 7 & 8 & 9 & 10 & 11 & 12 & 13 & 14 & 15 \\
\hline Exp. 1 & - & - & - & - & + & + & + & + & + & + & + & + & $\pm^{*}$ & - \\
& $(1)$ & $(1)$ & $(1)$ & $(2)$ & $(2)$ & $(1)$ & $(1)$ & $(2)$ & $(2)$ & $(2)$ & $(2)$ & $(4)$ & $(4)$ & $(3)$ \\
Exp. 2 & & & & & - & - & - & + & + & + & + & + & + & - \\
& & & & & $(2)$ & $(1)$ & $(1)$ & $(1)$ & $(1)$ & $(1)$ & $(1)$ & $(1)$ & $(2)$ & $(1)$ \\
\hline
\end{tabular}

* 2 animals were positive, 2 negative.

Artificial induction of the maternal pregnancy reaction in the ferret is comparable to the induction of deciduomata in laboratory rodents although no decidual cells are formed in the ferret (Beck, 1974). In the rat, De Feo (1963) reported that a deciduomal response to 'supramaximal' stimuli (e.g. scratching the endometrium) was attained earlier (by $12.00 \mathrm{~h}$ on Day 3 ) than that to 'non-traumatic' stimuli such as intraluminally injected chemical inducers (sensitivity limited to the 4th day). An intraluminal silk thread probably constitutes a 'supramaximal' stimulus in the ferret and the period 
of response to this trauma was longer than that in the rat. The results of Exp. 1 do not exclude the possibility that the endometrial response to a thread inserted before Day 12 is due to the presence of that thread on or around Day 12 but the results of Exp. 2 show that uterine sensitivity is restricted to a relatively short period around Day 12 .

The ability of the ferret uterus to produce a maternal pregnancy reaction appears to be related to the hormonal events associated with pregnancy. Plasma progesterone levels change little during the first 5-6 days after mating but increase rapidly to reach peak values at about Day 12, decreasing steadily after about Day 15 (Heap \& Hammond, 1974). Induction of the reaction became possible when progesterone levels were rising, and there was no reaction after Day 14. Unconjugated oestrogens were not detected in the plasma of pregnant and pseudopregnant ferrets by Heap \& Hammond (1974) and it is likely, therefore, that the production of a maternal pregnancy reaction in the ferret is progesterone-dependent, a view supported by the observation of Wu \& Chang (1973) that progesterone only is required for implantation and subsequent embryonic development in the ferret.

We are grateful to the Wellcome Trust for a grant in aid of research.

\section{References}

BECK, F. (1974) The development of a maternal pregnancy reaction in the ferret.J. Reprod. Fert. 40, 61-69.

DE FEO, V.J. (1963) Determination of the sensitive period for the induction of deciduomata in the rat by different inducing procedures. Endocrinology 73, 488-497.
Heap, R.B. \& Hammond, J., JR (1974) Plasma progesterone levels in pregnant and pseudopregnant ferrets. J. Reprod. Fert. 39, 149-152.

WU, J.T. \& CHANG, M.C. (1973) Hormonal requirement for implantation and embryonic development in the ferret. Biol. Reprod. 9, 350-355.

Received 21 May 1976 